\title{
Chemistry of Tissues
}

\section{CHONDROITIN FROM CARTILAGE}

\author{
By H. G. BRAY, J. E. GREGORY AND M. STACEY, Chemistry Department, \\ The University, Birmingham
}

(Received 7 February 1944)

Mucoproteins, mucoids, and glycoproteins belong to the class of compound constituted of protein and carbohydrate in combination, a recent new classifcation of which has been given by one of us (Stacey, 1943). The discovery that compounds of this type give rise on hydrolysis to sugars was made by Eichwald (1865), and since that time much scattered and fragmentary evidence concerning their constitution and behaviour has been reported.

Mucoproteins were roughly distinguished from other proteins by the fact that they formed viscous solutions in water from which they, could readily be precipitated in the cold by the addition of acetic acid. Eichwald studied the mucins of Helix pomatia, lymph, thymus, and salivary glands, and found that protein-carbohydrate complexes could be obtained from each of these sources, findings which were corroborated by later workers. Owing to the difficulty at that time of distinguishing readily between individual sugars, Eichwald wrongly concluded that the reducing substance which was produced by the hydrolysis of mucoproteins was glucose. Subsequent investigations by other workers, including Obolenski (1871) and Wolfenden (1884), showed, however, that this substance differed from glucose in that it contained nitrogen; while Müller (1901), by isolating from the mucin of bronchial mucus both a benzoyl derivative and the hydrochloride of chitosamine, showed that the reducing substance was an amino sugar. Landwehr (1882) considered that the mucin of $H$. pomatia contained not a simple sugar, but a $\mathrm{N}$-free polysaccharide of the same type as occurs in the plant gums. While $\mathrm{N}$-free carbohydrates. do exist in some mucoproteins, $\mathbf{N}$ usually is present and is in part present as amino-sugar residues. Speculation arose early as to whether there was chemical combination between the protein and polysaccharide in mucoproteins, or whether, as Landwehr considered to be the case, they were present together in the form of a mechanical mixture. It is now generally accepted that they exist in chemical union, possibly in the form of a salt-like combination.

As a result of numerous investigations it was recognized that two fairly well-defined polysaccharides, namely, chondroitin sulphuric acid (herein termed chondroitin sulphate) and mucoitin sulphuric acid, were constituents of many mucoproteins, and these, especially the former, have been the subject of most of the detailed work which has been carried out in this field. Many mucopolysaccharides too (Meyer, 1938; Stacey, 1943) have been isolated from a correspondingly large number of sources, but there is little agreement among workers as to their individuality and constitution.

Levene (1925) devoted considerable care to the isolation of many mucoproteins and mucopolysaccharides, but no structural investigations were satisfactorily completed. Indeed, the only polysaccharide in this class which has been investigated in detail is that obtained from ovomucoid (Stacey \& Woolley, 1940, 1942).

The group of acid mucopolysaccharides which contain organic sulphate residues includes heparin, the blood anticoagulant factor, as well as chondroitin sulphate and mucoitin sulphate from gastric mucin and possibly types of hyaluronic acid. From the preliminary examination of these carbohydrates all three appear to be similar in composition, consisting of $N$-acetyl amino sugars combined with glucuronic acid residues and esterified with $\mathrm{H}_{2} \mathrm{SO}_{4}$. In chondroitin sulphate the amino sugar is chondrosamine (2-aminogalactose or 2-aminotalose) (Levene, 1925), although in mucoitin sulphate (Levene, 1925) and in heparin (Jorpes \& Bergström, 1937) the sugar is glucosamine. Chondroitin sulphate occurs in connective tissue, but its chief sources are cartilage from nasal septa, tendons, aorta, trachea, and sclera. It is perhaps the most readily accessible sulphurcontaining polysaccharide. Mucoitin sulphate is found in cornea and gastric mucin, while heparin occurs in many organs, the best source yet discovered being the liver. Chondroitin sulphate, in common with other sulphated polysaccharides, exhibits a weak anti-coagulant action. Since chondroitin sulphate is probably related structurally to heparin, an investigation of its constitution may give information of use in the study both of heparin and of other carbohydrate sulphuric esters.

Chondroitin sulphate was first obtained by Fischer \& Boedeker (1861), and it was not until 1884 that a reasonably pure sample was prepared by Krukenberg (1884). Methods of preparation and, consequently, the purity of the specimens obtained have not greatly improved since that time. The first constitutional studies were made by Schmiedeberg (1891) and, although his conclusions are not always satisfactorily founded upon experimental evidence, he at least is responsible for the basis of the present-day conception of the structure of chondroitin sulphate.

Levene's (1925) conception of chondroitin sulphate is that of a tetrasaccharide compound of glucuronic acid (2 units) and chondrosamine (2 units) conjugated with $\mathrm{H}_{2} \mathrm{SO}$, residues. On hydrolysis with $\mathrm{HCl}$ it gives a disaccharide 'chondrosin' which is formed by the union of one residue to chondrosamine with one of glucuronic acid, the points of attachment between which are assumed.

K. Meyer and his colleagues have conducted many careful analytical and preparative studies on sulphated polysaccharides, including chondroitin sulphate. Thus Meyer, Palmer \& Smyth (1937) and Meyer (1938) studied the complexes which chondroitin sulphate forms with proteins. They concluded that the complexes were salts involving the - $\mathrm{COOH}$ and $-\mathrm{SO}_{3} \mathrm{H}$ groups in chondroitin sulphate and $-\mathrm{NH}_{2}$ groups in the proteins. The interesting suggestion 
was made that hyaline cartilage is a salt of chondroitin sulphate with a protein similar to gelatin, and the resemblance of artificial edestin-chondroitin sulphate fibres to natural elastic fibres of connective tissue was noted. Meyer \& Smyth (1937) described a method of preparing chondroitin sulphate from cartilage, which involved an extraction with $10 \% \mathrm{CaCl}_{2}$ solution followed by deproteinization. The products differed slightly from the chondroitin sulphates described above in having $\mathrm{N}, 2.95 \% ; \mathrm{S}, 5.8 \%$; and $[\alpha]_{D}-17^{\circ}$. These methods appear to cause very little degradation of the molecule, particularly with respect to hydrolysis of sulphate residues. No structural details were presented by the authors.

The investigations described below were begun some years ago and were unavoidably interrupted when only the preliminary stages had been carried out. However, sufficient evidence has been accumulated to show that chondroitin possesses a complicated branched chain structure and that Levene's (1925) formula for chondroitin sulphate is no longer tenable.

\section{EXPERIMENTAL}

Preparation of chondroitin sulphate. (1) From nasal septa. The polysaccharide was prepared from the nasal septa of cattle by a modification of the method of Levene (1925). The septa were freed from flesh, bone, fat and other matter, finely chopped and kept for 2-3 days in contact with $2 \%$ aqueous $\mathrm{KOH}$. The resulting viscid liquid was filtered through cloth and neutralized with glacial acetic acid. $\mathrm{BaCO}_{3}(100 \mathrm{~g} . / \mathrm{l}$.) was then added and the mixture heated on a boiling water-bath for 8-10 hr. The filtered solution was concentrated and the crude polysaccharide, precipitated by adding glacial acetic acid ( $8 \mathrm{vol}$.), was filtered and washed with ethanol. It was purified by dissolving in dilute $\mathrm{KOH}$ (pH about 8.0); the undissolved matter was removed (centrifuge) and the product in the supernatant liquid precipitated with ethanol (3 vol.). The polysaccharide, in the form of the crude K-salt, was separated (centrifuge), washed with absolute ethanol and ether, and dried in a vacuum. It was a white amorphous powder having $[\alpha]_{D}^{20)^{\circ}}-26 \cdot 2^{\circ}$; ash (K), $19 \cdot 2 \%$ (cf. Table 1 ).

(2) From bovine trachea, etc. The tracheae were freed from flesh as above, cut into small pieces and dissolved rapidly in $\mathrm{N}-\mathrm{NaOH}$ at $70^{\circ}$. The resulting solution was neutralized with acetic acid and heated with $\mathrm{BaCO}_{3}$ (100 g./l.) for $6 \mathrm{hr}$. The solid material was then separated and washed with water (centrifuge) and the supernatant liquid treated with a large excess of glacial acetic acid to precipitate the polysaccharide, which was separated (centrifuge) and further purified, either by Sevag's (1934) method or by repeated reprecipitation from aqueous solution by means of ethanol. It was washed with absolute ethanol and ether and then dried.

No other element except $\mathrm{Na}$ was detected in the ash from the trachea polysaccharide, and on this assumption the equivalent weight of this sample was 550. It is considered, however, that, since the products contain both free $-\mathrm{COOH}$ groups and $-\mathrm{SO}_{3} \mathrm{H}$ groups, equivalent weights obtained by direct titration are of little value.

Reprecipitation of the polysaccharide from acid solution. Attempts were made to reduce the ash content of the polysaccharide by reprecipitation by ethanol from dilute $\mathrm{HCl}$. In the case of the septa polysaccharide after a single reprecipitation, the ash content was $11.4 \%$ (weighed as sulphate) and the rotation $[\alpha]_{D}-23^{\circ}$ in water. This polysac. charide was acid in solution and its equivalent weight determined by titration with $0.01 \mathrm{~N}-\mathrm{NaOH}$ was 538 . Further precipitation from dilute $\mathrm{HCl}$ resulted in a further reduction in the ash content, but after six precipitations the polysaccharide was reducing to Fehling's solution, and had an ash content of $6.3 \%$ (as sulphate). The ash could not be removed by further precipitation. Other samples of polysaccharide gave comparable results. The reducing nature of the product may indicate that in the natural chondroitin sulphate some reducing groups are substituted by sulphate groups.

Autolysis of chondroitin sulphate. The polysaccharide obtained by a single reprecipitation from acid solution (see above) was non-reducing, but, on being heated in aqueous solution on a water-bath for $5 \mathrm{hr}$., became strongly reducing, suggesting that autolysis had taken place.

Preparation of degraded chondroitin. The polysaccharide was dissolved in $0.1 \mathrm{~N} \cdot \mathrm{H}_{2} \mathrm{SO}_{4}(20 \mathrm{~g} / / \mathrm{l}$.$) and heated on a$ water bath for $30 \mathrm{hr}$.; $[x]_{D}^{2 v^{\circ}}-26^{\circ} \rightarrow-5^{\circ}(c, 0 \cdot 2)$ (constant value). The acid was then neutralized with $\mathrm{BaCO}_{3}$, the filtered solution concentrated under diminished pressure, and the degraded polysaccharide precipitated with ethanol (5 vol.). It was isolated in the usual way. The supernatant fluid contained a small amount of syrupy material $(4 \%)$ which gave a positive test for amino sugar, and contained sulphate residues. This syrup probably was chondrosamine sulphate.

'Degraded chondroitin', an oligosaccharicle, was nonreducing to Fehling's solution and contained traces only of sulphate residues. The $\mathrm{Ba}$ salt had ash $\left(\mathrm{BaSO}_{4}\right) \mathbf{2 5 . 0} \%$ and an equivalent weight of 465 , which corresponds to that of a trisaccharide.

Preparation of acetylated degraded chondroitin. The acetylation was carried out by allowing a suspension of the degraded polysaccharide, in pyridine containing acetic anhydride, to shake for $48 \mathrm{hr}$. at room temperature. The reaction mixture was centrifuged and the supernatant liquid concentrated to a syrup. The acetylated derivative of the degraded polysaccharide was precipitated from a chloroform solution of this syrup by the addition of excess light petroleum. The solid layer, which was separated by centrifuging, was reacetylated as before, this process being repeated until the whole of the degraded polysaccharide had been acetylated. The product was a yellow powder with OAc, $38 \%$.

Methylation of acetylated degraded chondroitin. The acetyl derivative prepared as above (10 $\mathrm{g}$ :) was dissolved in water

Table 1. Properties of different specimens of chondroitin sulphate

\begin{tabular}{|c|c|c|c|c|c|c|}
\hline Source & $\begin{array}{l}\text { Ash, as } \\
\text { sulphate } \\
(\%)\end{array}$ & $\begin{array}{l}\text { Inorganic } \\
\text { elements }\end{array}$ & {$[\alpha]_{D}^{17^{\circ}}$} & $\begin{array}{l}N \\
(\%)\end{array}$ & $\begin{array}{c}S \\
(\%)\end{array}$ & $\begin{array}{l}\text { OAc } \\
(\%)\end{array}$ \\
\hline $\begin{array}{l}\text { Bovine nasal septa } \\
\text { Bovine trachea } \\
\text { Human trachea } \\
\text { Human cartilage }\end{array}$ & $\begin{array}{l}19 \cdot 2 \\
13 \cdot 05 \\
15 \cdot 0 \\
34 \cdot 6\end{array}$ & $\begin{array}{l}\mathrm{K}, \mathrm{Ba} \\
\mathrm{Na} \\
\mathrm{Na} \\
\mathrm{Na}, \mathrm{Ba}\end{array}$ & 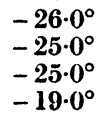 & $\begin{array}{l}3 \cdot 0 \\
4 \cdot 3 \\
4 \cdot 0 \\
4 \cdot 9\end{array}$ & $\begin{array}{l}\mathbf{2 \cdot 3} \\
\mathbf{2} \cdot \mathbf{5} \\
\mathbf{2} \cdot \mathbf{5} \\
\mathbf{4} \cdot \mathbf{1}\end{array}$ & $\begin{array}{l}8 \cdot 5 \\
8 \cdot 6 \\
8 \cdot 4 \\
7 \cdot 4\end{array}$ \\
\hline
\end{tabular}


(100 ml.), and carbon tetrachloride $(300 \mathrm{ml}$.) added. The mixture was stirred with methyl sulphate $(80 \mathrm{ml}$.$) , and$ $30 \%$ aqueous $\mathrm{NaOH}$ solution $(170 \mathrm{ml}$.) was run in over a period of $1 \mathrm{hr}$. Methyl sulphate (75 ml.) and alkali (158 ml.) were then added simultaneously over a period of $2 \mathrm{hr}$., and the mixture stirred at $35^{\circ}$ for $2 \mathrm{hr}$. Some of the $\mathrm{Na}_{2} \mathrm{SO}_{4}$ crystallized and was filtered off. The filtrate was concentrated and the product remethylated in carbon tetrachloride $(250 \mathrm{ml}$.) with methyl sulphate $(40 \mathrm{ml}$.) and $30 \% \mathrm{NaOH}$ $\left(85 \mathrm{ml}\right.$.). The mixture was stirred at $50^{\circ}$ for $12 \mathrm{hr}$. and the methylated material separated by fractional crystallization of the insoluble matter by means of ethanol and acetone.

The product was further methylated with methyl iodide and $\mathrm{Ag}_{2} \mathrm{O}$. The final product (OMe, $30.5 \%$ ) was separated into four fractions by the addition of light petroleum to a chloroform solution.

Two separate batches were methylated and.thus eight fractions (OMe, $25 \cdot 5-39 \cdot 9 \%$ ) were separated. Investigation showed that most of these contained a low percentage of sulphate residues and they were acid to congo red. In addition it was found impossible to increase their methoxyl content by further methylation, so that it was necessary to recombine them in order to remove the sulphate residues, part of which seemed to be present as ester sulphate groups. The sulphate was removed in the manner described below.

Preparation of partly methylated degraded chondroitin. The combined fractions in the form of a syrup $(6 \mathrm{~g}$.) were dissolved in a little water and $0.1 \mathrm{~N}-\mathrm{NaOH}(150 \mathrm{ml}$.) added. The solution was heated on a boiling water-bath for $4 \frac{1}{2} \mathrm{hr}$., neutralized with dilute $\mathrm{H}_{2} \mathrm{SO}_{4}$, and concentrated in a vacuum to $50 \mathrm{ml}$. Dialysis, with a cellophan membrane, was shown to be ineffective as a method of removing the inorganic sulphate, since the carbohydrate passed through the membrane, and the following treatment was substituted. Excess of a neutral aqueous solution of lead acetate (unalytical reagent) was added to the concentrated solution and the resulting precipitate of $\mathrm{PbSO}_{4}$ removed (centrifuge). The $\mathrm{Pb}$ in solution was removed by means of $\mathrm{H}_{2} \mathrm{~S}$, and the solution, filtered through a charcoal pad, was concentrated to a syrup which now gave no test for sulphate residues. It was further purified by repeatedly dissolving it in absolute ethanol, concentrating the solution and filtering off the inorganic material which separated.
Preparation of fully methylated degraded chondroitin. The above syrup, which was an acid, was dissolved in acetone containing a few ml. of dry methanol, and methylated and esterified by means of $\mathrm{Ag}_{2} \mathrm{O}$ and methyl iodide in the usual way, two treatments being given. The methylated product, now soluble in dry acetone, was isolated in the form of a clear syrup which contained some AgI.

Hydrolysis of methylated degraded chondroitin. A trial hydrolysis with $8 \%$ hydrogen chloride in methanol was carried out on a small quantity of the syrup $(0.5 \mathrm{~g}$.). The mixture was refluxed on a boiling water-bath. $\alpha_{D}+0.035^{\circ}$ (initial value); $+0.09^{\circ}(1.5 \mathrm{hr}) ;.+0.15^{\circ}(4.15 \mathrm{hr}) ;.+0.19^{\circ}$ $\left(5.9 \mathrm{hr}\right.$.); $+0.19^{\circ}(7.9 \mathrm{hr}$.) (constant value). At the end of $8 \mathrm{hr}$. the solution was neutralized with $\mathrm{Ag}_{2} \mathrm{CO}_{3}$ and the filtered solution concentrated to a thin syrup. This was extracted with ether, giving an ether-soluble fraction and an ether-insoluble fraction. The process was then repeated on a larger scale.

Investigation of the ether-soluble fraction. The ether-soluble fraction was obtained as a clear mobile syrup. A sample portion $(0.35 \mathrm{~g}$.) was distilled in a high vacuum and gave the fractions shown in Table $2 \mathrm{~A}$.

Isolation of 2:3:4-trimethyl- $\alpha$-methylglucuronoside. Fractions 1 and 2 (Table $2 \mathrm{~A}$ ) were separately dissolved in a little dry methanol, the solution saturated with $\mathrm{NH}_{3}$ and kept at $0^{\circ}$ for 2 days. They were then concentrated to syrups which, on drying, crystallized completely. The products were recrystallized from an ethanol-ether mixture, light petroleum being added until the solution just became cloudy. From both fractions fine needle-like crystals were obtained which melted at $182-183^{\circ}$, alone or in admixture with an authentic specimen of the amide of 2:3:4-trimethyl- $\alpha$ methylglucuronoside. The fact that this product was obtained shows that the original polysaccharide must contain glucuronic acid as an end-group.

The remainder of the ether-soluble fraction was then distilled and the fractions shown in Table 2 B were obtained.

Investigation of ether-insoluble fraction. This fraction (OMe, $31 \cdot 8 \%$ ) contained $\mathrm{N}$. It was an extremely viscous, clear syrup, with an acid reaction.

This fraction was first treated with dry methanol containing acetic anhydride ( $5 \%$ of total weight) to acetylate the amino group. The mixture was kept for $24 \mathrm{hr}$. and then

Table 2. Properties of the ether-soluble methylated fraction

\begin{tabular}{|c|c|c|c|c|c|}
\hline Fraction & $\begin{array}{l}\text { Weight } \\
\text { (g.) }\end{array}$ & $\begin{array}{c}\text { b.p. } \\
\text { (bath temp.) }\end{array}$ & $\alpha_{D}^{18^{\circ}}$ & $\begin{array}{l}\mathrm{OMe} \\
(\%)\end{array}$ & Description \\
\hline \multicolumn{6}{|c|}{ A. Distillation of a sample portion } \\
\hline 1 & 0.0564 & $\begin{array}{c}120-125^{\circ} \\
(0.03 \mathrm{~mm} .)\end{array}$ & $1 \cdot 4490$ & $48 \cdot 8$ & Pale brown mobile syrup \\
\hline 2 & $0 \cdot 1105$ & $\begin{array}{c}125-134^{\circ} \\
(0.04 \mathrm{~mm} .)\end{array}$ & $1 \cdot 4520$ & $51 \cdot 65$ & Pale yellow mobile syrup \\
\hline Residue & $0 \cdot 1735$ & Above $165^{\circ}$ & - & $30 \cdot 4$ & Dark brown viscous syrup, soluble in ether \\
\hline \multicolumn{6}{|c|}{ B. Distillation of the remainder } \\
\hline 1 & 0.8840 & $\begin{array}{c}115-125^{\circ} \\
(0.025 \mathrm{~mm} .)\end{array}$ & $1 \cdot 4522$ & $50 \cdot 45$ & Mobile syrup \\
\hline 2 & $0 \cdot 1638$ & $\begin{array}{l}125-140^{\circ} \\
(0.02 \mathrm{~mm} .)\end{array}$ & $1 \cdot 4556$ & $48 \cdot 1$ & Less mobile syrup \\
\hline 3 & $0 \cdot 1292$ & $\begin{array}{l}140-165^{\circ} \\
(0.02 \mathrm{~mm} .)\end{array}$ & $1 \cdot 4570$ & $34 \cdot 0$ & Viscous syrup \\
\hline $\begin{array}{c}\text { Residue } \\
4\end{array}$ & 0.4590 & Abnve $165^{\circ}$ & - & - & Very viscous syrup \\
\hline
\end{tabular}


a little water added to decompose the excess acetic anhydride. The solvent and acetic acid were removed by distillation under reduced pressure at $40^{\circ}$. The resulting syrupy product was more mobile and no longer acid. On distillation in a high vacuum a small amount of a very viscous distillate was obtained at $165-180^{\circ}(0.015 \mathrm{~mm}$.), which was nucleated with an authentic specimen of fully methylated $\boldsymbol{N}$-acetyl$\alpha$-methyl-chondrosaminide. After the addition of a little ethyl acetate the material readily crystallized. Recrystallized from ethyl acetate the fine, needle-like crystals had a melting-point $179-180^{\circ}$, alone or in admixture with $3: 4: 6$ trimethyl- $N$-acetyl- $\alpha$-methylchondrosaminide.

The addition of a little ethyl acetate to the undistilled residue, and its inoculation with the same chondrosamine derivative as above, brought about further crystallization.

At this stage further investigation of the various fractions had to be suspended.

\section{RESULTS}

In all samples of chondroitin sulphate the amino group of the chondrosamine residues was acetylated. The product was difficult to acetylate and methylate fully and so was first degraded by hydrolysis with $0 \cdot 1 \mathrm{~N} \cdot \mathrm{H}_{2} \mathrm{SO}_{4}$ in order to give a product of lower molecular weight and to remove the sulphate residues. The hydrolysis liberated a small amount (4\%) allocation of the position of the sulphate residues is to be decided.

To complete the removal of sulphate groups the fractions were combined and again submitted to hydrolysis, this time with $0 \cdot 1 \mathrm{~N}-\mathrm{NaOH}$. The sulphate-free product was still acid to congo red, indicating that the carboxyl groups of part at least of the glucuronic acid units were not now engaged in linkage with the rest of the molecule. The syrup was then treated with $\mathrm{Ag}_{2} \mathrm{O}$ and methyl iodide to complete the methylation, and to esterify the free carboxyl groups present. 'During the purification of the fully methylated material some difficulty was encountered, due possibly to the formation of a complex between the AgI and the free amino groups in the polysaccharide, which had not been reacetylated after the alkaline hydrolysis (cf. Irvine \& Hynd, 1912; Stacey \& Woolley, 1940). This complex was, however, decomposed when the methylated material was hydrolyzed with $8 \%$ hydrogen chloride in methanol.

Part (33\%) of the material hydrolyzed on treatment with ammonia in methanol gave the crystalline amide of 2:3:4-trimethyl- $\alpha$-methylglucuronoside (I) which was identical with an authentic specimen.

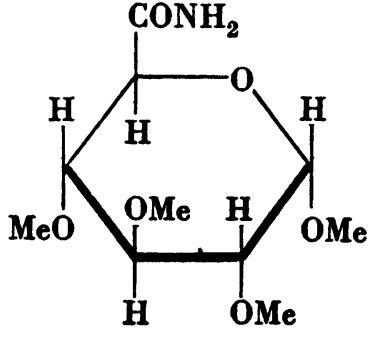

(I)

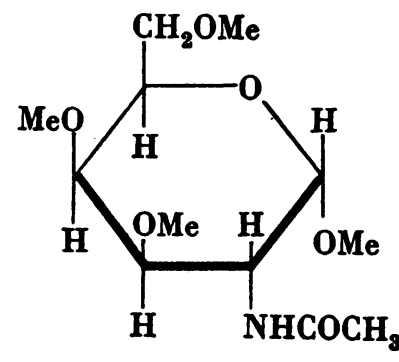

(II) of amino sugar. The degraded product, for which the name 'degraded chondroitin' was retained, was acetylated with acetic anhydride and pyridine at room temperature. The acetylated degraded chondroitin was simultaneously deacetylated and methylated, initially with methyl sulphate and $\mathrm{NaOH}$, and subsequently with methyl iodide and $\mathrm{Ag}_{2} \mathrm{O}$. The product was separated by precipitation into fractions which had methoxyl contents varying from 2.5 to $40 \%$. In the earlier experiments it was found impossible to methylate further the fractions with lower methoxyl content, when methyl iodide and $\mathrm{Ag}_{2} \mathrm{O}$ were used. It was later discovered that the reason for this failure lay in the fact that the hydrolysis with dilute acid had not completely removed the sulphate residues. The carbohydrate derivative so produced, which contains both methoxyl groups and $\mathrm{H}_{2} \mathrm{SO}_{4}$ residues, appears to be novel and will undoubtedly be of importance when the
The production of this fully methylated compound from the methylated polysaccharide establishes a number of facts. First, clear proof is furnished for the first time of the presence of glucuronic acid as a constituent of chondroitin, and secondly it proves that about one-half of the glucuronic acid residues must constitute terminal groups in the polysaccharide. Moreover, it is apparent that the linkage with the rest of the molecule must involve position 1 of these glucuronic acid residues, i.e. they are attached by glycosidic links.

The crystalline substance from the ether-insoluble fraction was identified as 3:4:6-trimethyl- $\boldsymbol{N}$-acetyl$\alpha$-methylchondrosaminide (II), which had previously been prepared in this department from chondrosamine hydrochloride (cf. Levene, 1941), the yield indicating that about $33 \%$ of the product of hydrolysis of methylated degraded chondroitin consisted of $\boldsymbol{N}$-acetyl chondrosamine which was 
only partly methylated. The methoxyl content of this product indicated that it consisted mainly of a dimethyl- $\boldsymbol{N}$-acetyl-methylchondrosaminide.

The viscous volatile fraction and the undistilled residue obtained from the distillation of the ethersoluble fraction had methoxyl contents of 30-34\% and were $\mathbf{N}$-free and acid in reaction. These have not yet been fully examined, but since they can be methylated further to give fully methylated glucuronic acid, the presence in them is suggested of a dimethyl glucuronic acid residue. (A dimethyl glucuronic acid requires $\mathrm{OMe}, 28 \%$, and a dimethyl glucuronolactone, OMe, $30 \%$.)

\section{DISCUSSION}

At the stage which this investigation has reached it is possible to set forth some pertinent facts regarding the structure of chondroitin sulphate. Thus chondroitin sulphate occurs in cartilage in the form of a high molecular muco-protein from which the protein constituent can be removed by mild saponification. The protein-free carbohydrate is still a high polymer constituted of units of $\boldsymbol{N}$-acetyl chondrosamine, glucuronic acid, and sulphuric acid. The last-named residues can be split off by hydrolysis with strong alkali or weak mineral acid. The acid hydrolysis causes some degradation with the liberation of a small percentage of a labile amino sugar, but the residual 'degraded chondroitin' is nonreducing to Fehling's solution. Its solutions, as well as those of its acetylated and methylated derivatives, have low viscosities and the compounds readily dialyze through cellophan membranes. Thus the molecular weight of degraded chondroitin is relatively low, the minimum possible being that of a trisaccharide.

From the isolation of a high percentags of terminal glucuronic acid groups it is clear that the molecule is of the branched chain type. (Stacey \& Woolley, 1942), and the carboxyl groups of some of the glucuronic acid units may be involved as polymeric links in chondroitin. A complete knowledge of the structure of chondroitin sulphate must await further study, particularly of the identities of the partially methylated chondrosamine and glucuronic acid portions. In this connexion a new aspect of the problem has been presented by the work of Percival \& Soutar (1940) and Duff \& Percival (1941), who have shown that the removal of sulphate groups from hexoses by means of $\mathrm{Ba}(\mathrm{OH})_{2}$ gives rise to anhydro sugars. A search will need to be made for such compounds among the hydrolytic products of methylated chondroitin.

\section{SUMMARY}

1. Chondroitin sulphate was isolated from the nasal septa of cattle and from bovine and human trachea.

2. It was degraded and methylated to give fully methylated, sulphate-free degraded chondroitin of relatively low molecular weight. From an acid hydrolysate, derivatives of glucuronic acid and chondrosamine were isolated and characterized as the amide of 2:3:4-trimethyl- $\alpha$-methylglucuronoside and 3:4:6-trimethyl- $N$-acetyl- $\alpha$-methylchondrosaminide respectively.

3. Three facts were established: first, glucuronic acid and chondrosamine are constituents of the molecule of chondroitin sulphate; secondly, part at least of the glucuronic acid residues is present as terminal groups; and thirdly, the linkage between these residues and the remainder of the molecule is of a glycosidic nature, involving $C_{1}$ of the glucuronic acid residues. Chondroitin sulphate possesses a structure of the branched chain type.

The authors thank Prof. W. N. Haworth, F.R.S., for his interest in this work.

\section{REFERENCES}

Duff, R. B. \& Percival, E. G. V. (1941). J. chem. Soc. p. 830. Eichwald, E. (1865). Liebigs Ann. 134, 177.

Fischer, C. \& Boedeker, C. (1861). Liebigs Ann. 117, 111. Irvine, J. C. \& Hynd, A. (1912). J. chem. Soc. 101, 1128. Jorpes, E. \& Bergström, S. (1937). J. biol. Chem. 118, 447. Krukenberg, C. F. W. (1884). Z. Biol. 20, 307.

Landwehr, H. A. (1882). Hoppe-Seyl. Z. 6, 741.

Levene, P. A. (1925). Hexosamines and Mucoproteins. London: Longmans Green.

(1941). J. biol. Chem. 140, 267.

Meyer, K. (1938). Cold Spr. Haih. Symp. Quant. Biol. $6,91$.

Palmer, J. W. \& Smyth, E. M. (1937). J. biol. Chem. 119, 501.
Meyer, K. \& Smyth, E. M. (1937). J. biol. Chem. 119, 507.

Müller, F. (1901). Z. Biol. 42, 468.

Obolenski, S. (1871). Med. chem. Unters. v. Hoppe Zeyler, 4, 590.

Percival, E. G. V. \& Soutar, T. H. (1940). J. chem. Soc. p. 1475.

Schmiedeberg, 0. (1891). Arch. exp. Path. Pharmak. 28, 355.

Sevag, M. G. (1934): Biochem. Z. 273, 419.

Stacey, M. (1943). Chem. Ind. 62, 110.

— \& Woolley, J. M. (1940). J. chem. Soc. p. 184.

- (1942). J. chem. Soc. p. 550.

Wolfenden, R. N. (1884). J. Physiol. 5, 91. 